\title{
A durable P2-type layered oxide cathode with superior low-temperature performance for sodium-ion batteries
}

\author{
Yong $\mathrm{Li}^{1,2}$, Yufeng Zhao ${ }^{1,2^{*}}$, Xiaochen Feng, ${ }^{2,3}$, Xuan Wang ${ }^{2}$, Qinhao Shi ${ }^{2}$, Jing Wang ${ }^{3}$, Juan Wang ${ }^{*}$, \\ Jiujun Zhang ${ }^{2}$ and Yanglong $\mathrm{Hou}^{4 *}$
}

\begin{abstract}
To power large-scale energy storage systems, sodium-ion batteries (SIBs) must have not only high-energy density but also high performance under a low-temperature (LT) environment. P2-type manganese oxides with high specific capacity are promising cathode candidates for SIBs, but their LT applications are limitedly explored. We proposed a P2-type $\mathrm{Na}_{0.67} \mathrm{Ni}_{0.1} \mathrm{Co}_{0.1} \mathrm{Mn}_{0.8} \mathrm{O}_{2}$ material with outstanding $\mathrm{LT}$ performance prepared through reasonable structure modulation. The material offers an excellent $\mathrm{Na}^{+}$diffusion coefficient (approximately $10^{-9}-10^{-7.5} \mathrm{~cm}^{2} \mathrm{~s}^{-1}$ ) at $-20^{\circ} \mathrm{C}$, a superior LT discharge capacity of $147.4 \mathrm{~mA} \mathrm{~h} \mathrm{~g}^{-1}$ in the $\mathrm{Na}$ half-cell system, and outstanding LT full cell performance (energy density of $358.3 \mathrm{~W} \mathrm{~h} \mathrm{~kg}^{-1}$ ). Various characterisations and density function theory calculations results show that the solid solution reaction and pseudocapacitive feature promote the diffusion and desolvation of $\mathrm{Na}^{+}$from the bulk electrode to interface, finally achieving superior electrochemical performance at LT.
\end{abstract}

Keywords: sodium-ion batteries, P2-type layered oxides, low temperature, structure modulation, pseudocapacitive feature

\section{INTRODUCTION}

Sodium-ion batteries (SIBs) have received considerable attention due to their excellent potential as viable alternatives to lithiumion batteries (LIBs) in cost-efficient large-scale energy storage systems and low-speed electric vehicles $[1,2]$. In addition to their cost, safety, and electrochemical performance, low-temperature (LT) properties are vital parameters for their practical applications in the commercial market [3-6]. Thermal management systems are used to ensure that SIBs operate over suitable and favourable temperature range; however, SIBs perform well at LT through not only thermal management but also novel cell design $[7,8]$.

Generally, sodium ions migrate from the electrolyte to the electrode/electrolyte interface and bulk electrode, which corresponds to solvation, desolvation and solid-state diffusion process, respectively. The specific capacities and rate performance can severely deteriorate when the ambient temperature falls to subzero or lower temperature [7,9-17]. LT limitations can be attributed to the reduced conductivity of electrolytes, high barrier for $\mathrm{Na}^{+}$desolvation within the electrode/electrolyte inter- face, and sluggish $\mathrm{Na}$ transport kinetics in solid active materials [18-22]. Electrodes with the crystal structure of $\mathrm{Na}$-super-ionic conductors, such as Prussian blue/carbon nanotube composites [23], $\mathrm{Na}_{3} \mathrm{~V}_{2}\left(\mathrm{PO}_{4}\right)_{3} / \mathrm{C}$ [24], $\mathrm{Na}_{3} \mathrm{~V}_{2}\left(\mathrm{PO}_{4}\right) \mathrm{O}_{2} \mathrm{~F}$ [25], and $\mathrm{Na}_{4} \mathrm{Fe}_{3}-$ $\left(\mathrm{PO}_{4}\right)_{2}\left(\mathrm{P}_{2} \mathrm{O}_{7}\right) / \mathrm{C}$ [26], are preferred for LT applications. However, their commercial LT application has been hindered due to a lack of rigorous synthesis methods and restricted theoretical capacities. Therefore, the development of high-performance electrode materials that can be charged/discharged at LT is urgent.

We analysed the kinetics, LT electrochemical properties, and storage mechanism of $\mathrm{P} 2-\mathrm{Na}_{0.67} \mathrm{MnO}_{2}(\mathrm{NM})$ under LT conditions. Our NM samples offer first LT discharge specific capacity of $108.3 \mathrm{~mA} \mathrm{~h} \mathrm{~g}^{-1}$ at $0.2 \mathrm{C}\left(1 \mathrm{C}=170 \mathrm{~mA} \mathrm{~h} \mathrm{~g}^{-1}\right)$, which corresponds to a capacity retention of only $52.3 \%$ and a poor rate capacity $\left(55 \mathrm{mAh} \mathrm{g}^{-1}\right.$ at $\left.10 \mathrm{C}\right)$. LT cycling stability is merely maintained for $<100$ cycles at $0.5 \mathrm{C}$. According to the kinetics analysis, ordered superstructures result in slow desodiation, which further leads to ultrahigh charge transfer resistance. Finally, for $\mathrm{Mn}$ sites, partial substitution with $\mathrm{Co} / \mathrm{Ni}$ having similar ionic radii and different redox potentials (Femi level) can effectively shield the electrostatic interactions of $\mathrm{Na}^{+} /$vacancy ordering and enlarge the Na layer distance with transition metal dioxide $\left(\mathrm{TMO}_{2}\right)$ slab contraction $[27,28]$. Thus, an excellent LT and plateau-free P2-type material, $\mathrm{Na}_{0.67} \mathrm{Ni}_{0.1} \mathrm{Co}_{0.1} \mathrm{Mn}_{0.8} \mathrm{O}_{2}$ (NNCM), was developed. The capacitor behaviour over the entire voltage range ensured both high $\mathrm{Na}^{+}$mobility and structural stability at $-20^{\circ} \mathrm{C}$. NNCM exhibited a high reversible capacity of $147.1 \mathrm{mAh} \mathrm{g}^{-1}$, an excellent rate capacity of $66.8 \mathrm{~mA} \mathrm{~h} \mathrm{~g}^{-1}$ at $10 \mathrm{C}$, and an ultrahigh capacity retention of $80 \%$ after 300 cycles at $-20^{\circ} \mathrm{C}$.

\section{EXPERIMENTAL SECTION}

Synthesis of NNCM, P2- $\mathrm{Na}_{0.67} \mathrm{Co}_{0.2} \mathrm{Mn}_{0.8} \mathrm{O}_{2}$ (NCM), P2$\mathrm{Na}_{0.67} \mathrm{Ni}_{0.2} \mathrm{Mn}_{0.8} \mathrm{O}_{2}$ (NNM), and $\mathrm{NM}$ cathode materials

All the reagents were purchased from Sigma-Aldrich and used without further purification. The NNCM cathode material was prepared using a typical sol-gel method. Citric acid $(17 \mathrm{mmol})$ was dissolved in deionised water $(50 \mathrm{~mL})$. Then, different amounts of sodium acetate trihydrate, nickel (II) acetate tetrahydrate, cobalt (II) acetate tetrahydrate, and manganese (II) acetate tetrahydrate, with the total amount of $17 \mathrm{mmol}$, were

\footnotetext{
${ }^{1}$ Shaanxi Key Laboratory of Nanomaterials and Nanotechnology, Xi'an University of Architecture and Technology, Xi'an 710055, China

${ }^{2}$ Institute for Sustainable Energy, College of Science, Shanghai University, Shanghai 200444, China

${ }^{3}$ Key Laboratory of Applied Chemistry, Yanshan University, Qinhuangdao 066000, China

${ }^{4}$ Department of Materials Science and Engineering, College of Engineering, Peking University, Beijing 100871, China

* Corresponding authors (emails: yufengzhao@shu.edu.cn (Zhao Y); juanwang168@gmail.com (Wang J); hou@pku.edu.cn (Hou Y))
} 
mixed according to the desired Na:Ni:Co:Mn ratio. After 30-min stirring, water in the solution was evaporated at $80^{\circ} \mathrm{C}$. Subsequently, precursors were dried at $70^{\circ} \mathrm{C}$ for $24 \mathrm{~h}$. For NNCM, the dried powder was calcined initially at $500^{\circ} \mathrm{C}$ for $12 \mathrm{~h}$ and then at $900^{\circ} \mathrm{C}$ for another $10 \mathrm{~h}$ in air. Finally, after natural cooling, the NNCM samples were obtained. For comparison, the NNM, NCM, and NM samples were synthesised using a similar process. Their chemical formulas were identified using inductively coupled plasma-atomic emission spectrometer (ICP-AES) tests (Table S1).

\section{Characterisation}

The crystalline phases of compounds were investigated through powder X-ray diffraction (XRD) on a D8 X-ray diffractometer using $\mathrm{Cu} \mathrm{Ka}$ radiation. The Rietveld refinement of XRD patterns was performed using the FullProf Rietveld program. The morphology and microstructure of the as-prepared materials were analysed through field-emission scanning electron microscopy (FESEM, Nova-450, 15kV) and transmission electron microscopy (TEM, JEOL JEM-2100F TEM, 200kV). Surface chemistry states were determined using X-ray photoelectron spectroscopy (XPS, PHI QUANTERA-II SXM).

\section{Computational details}

Density functional theory (DFT) calculations were performed using the Vienna $a b$ initio simulation package (VASP) within a $3 \mathrm{a} \times 4 \mathrm{~b} \times 1 \mathrm{c}$ supercell. The spin-polarised version of the Perdew-Burke-Ernzerhof functional under the generalised gradient approximation (GGA) was adopted to treat the exchange correlation energy. For the GGA + U-based DFT calculations, the $U$ values of $\mathrm{Ni}, \mathrm{Co}$, and $\mathrm{Mn}$ were $6.1,5.7$, and $4.0 \mathrm{eV}$, respectively. All the calculations were performed with an energy cut-off of $400 \mathrm{eV}$ until residual forces in the system became $<0.02 \mathrm{eV}^{-1}$ per unit cell. To calculate the energy difference between $\mathrm{Na}_{\mathrm{e}}$ and $\mathrm{Na}_{\mathrm{f}}$ sites, a $3 \mathrm{a} \times 4 \mathrm{~b} \times 1 \mathrm{c}$ supercell with one $\mathrm{Na}$ ion was constructed to prevent the Coulombic repulsion among $\mathrm{Na}$ ions. The difference in site energy can be calculated using the following equation [25]:

$\Delta E=E\left(\mathrm{Na}_{\mathrm{e}}\right)-E\left(\mathrm{Na}_{\mathrm{f}}\right)$,

where $E\left(\mathrm{Na}_{\mathrm{e}}\right)$ and $E\left(\mathrm{Na}_{\mathrm{f}}\right)$ are the total DFT energies of bulk models with an ion occupying $\mathrm{Na}_{\mathrm{e}}$ and $\mathrm{Na}_{\mathrm{f}}$ sites, respectively.

\section{Electrochemical measurement}

Cathodes were fabricated by blending active materials (80 wt \%), super $\mathrm{P}$ carbon black (10 wt\%), and polyvinylidene fluoride (10 wt\%). Then, the slurry obtained was applied onto an aluminium foil, and the foil was dried at $80^{\circ} \mathrm{C}$ for over $12 \mathrm{~h}$ in a vacuum oven. The mass loading of active materials was 1$1.2 \mathrm{mg} \mathrm{cm}^{-2}$. Half cells were assembled with 2032 type-coin cells in an Ar-containing dry box. The $\mathrm{Na}$ metal was used as an anode, and the electrolyte comprised $1 \mathrm{molL}^{-1} \mathrm{NaPF}_{6}$ in a solution of ethylene carbonate and propylene carbonate (1:1 by volume) with $5 \%$ fluoroethylene carbonate. Electrochemical tests, including charge/discharge performance analyses and galvanostatic intermittent titration technique (GITT), were conducted using the LAND battery-test instrument (CT2001A). A high-LT chamber (Fig. S1), with a temperature range of $-40-$ $60^{\circ} \mathrm{C}$, was used to obtain stable ambient temperature for investigations at 25 and $-20^{\circ} \mathrm{C}$. All the batteries were stored at specific temperature for a minimum of $1 \mathrm{~h}$ to attain the equilibrium between battery and chamber pre-set temperatures. Cyclic voltammetry (CV) and impedance were measured on the Chen Hua electrochemical station (CHI660E) by applying a 5-mV harmonic perturbation signal. Electrochemical impedance spectroscopy (EIS) spectra were acquired in the frequency of $100 \mathrm{kHz}$ to $10 \mathrm{MHz}$. For GITT measurements, cells were charged in the same voltage window at $0.1 \mathrm{C}$ for $30 \mathrm{~min}$, and then, were relaxed for $2 \mathrm{~h}$. The formula is as follows:

$D=\frac{4}{\pi \tau}\left(\frac{m_{\mathrm{B}} V_{\mathrm{m}}}{M_{\mathrm{B}} S}\right)^{2}\left(\frac{\mathrm{d} E_{\mathrm{s}}}{\mathrm{d} E_{\tau}}\right)^{2}$,

where $\tau$ is the time for an applied galvanostatic current. $M_{\mathrm{B}}$ and $m_{\mathrm{B}}$ are the molecular weight and mass, respectively, of the active material. $V_{\mathrm{m}}$ is the molar volume, $S$ is the surface area of the electrode, and $\Delta E_{\mathrm{s}}$ and $\Delta E_{\tau}$ are the steady-state (equilibrium) voltage and total change in the cell voltage $E$ during the current pulse, respectively.

\section{RESULTS AND DISCUSSION}

Fig. 1a and Figs S2-S5 show the XRD and Rietveld refined results of NM, NCM, NNM, and NNCM, respectively. All the diffraction peaks were assigned to a typical hexagonal structure (space group: $\mathrm{P6}_{3} / \mathrm{mmc}$ ). Table S2 presents the specific crystallographic data, atom coordinates, and occupancies of these compounds. The fitting results and shift of the (002) peak towards a relatively lower angle obtained after the co-substitution of cobalt and nickel indicated that lattice cell expansion along the $c$-axis and $\mathrm{TMO}_{2}$ layer contraction led to an increase in the interaction between TM and $\mathrm{O}$ and a decrease in the binding energy of $\mathrm{Na}$ and $\mathrm{O}$. Finally, ordered superstructures were effectively refrained, because double-ion substitution led to the further enlargement of the Fermi level difference between TMs. At $\mathrm{Na}_{\mathrm{e}}$ sites, a preferred occupancy was observed because of low electrostatic repulsion at this position, which can be commonly observed in NNCM compounds. XPS analyses were performed to confirm the oxidation states of $\mathrm{Mn}, \mathrm{Ni}$, and $\mathrm{Co}$ (Fig. $\mathrm{lb}$ and Fig. S6). The Mn 2p spectra of the two samples were similar, where the binding energy of $\mathrm{Mn}$ was between that of trivalent $\left(\mathrm{Mn} 2 \mathrm{p}_{3 / 2}, 641.2 \mathrm{eV}\right)$ and tetravalent $\left(\mathrm{Mn} \mathrm{2} \mathrm{p}_{3 / 2}, 642.6 \mathrm{eV}\right) \mathrm{Mn}$ states. Moreover, the NNCM sample showed a state considerably similar to the tetravalent state $[11,26]$, and the ratio of $\mathrm{Mn}^{4+}$ and $\mathrm{Mn}^{3+}$ for NNCM was higher than that for the pristine sample. The $\mathrm{Mn}^{4+}$ contents of the NNCM and pristine samples were $42.1 \%$ and $39.6 \%$, respectively. These results indicate that element doping leads to a decrease in high-spin $\mathrm{Mn}^{3+}$ formation, which further confirms the stable structure of NNCM compounds. $\mathrm{Co} / \mathrm{Ni}$ co-doping can expand the $\mathrm{Na}^{+}$layer spacing and accelerate $\mathrm{Na}^{+}$mobility (Fig. 1c). To analyze the visualised microstructure of NM and NNCM powders, the morphology and crystal structure information were acquired through FESEM and TEM, as plotted in Fig. 1d and Fig. S7. The NNCM particles exhibited a microflake structure, which highly promoted the electrode-electrolyte contact and shortened the diffusion distance. The widths of approximately 2.5 and $5.5 \AA$ between the neighbouring lattice fringes determined using high-resolution TEM (HRTEM) corresponded to the $d$-spacing values of the (100) and (002) planes, respectively, of the layered hexagonal structure of NNCM particles (Fig. 1e-g). The selected area electron diffraction (SAED) further confirmed that TM atoms were arranged in the typical hexagonal symmetry phase [27]. Moreover, energy-dispersive spectroscopy (EDS) mapping 

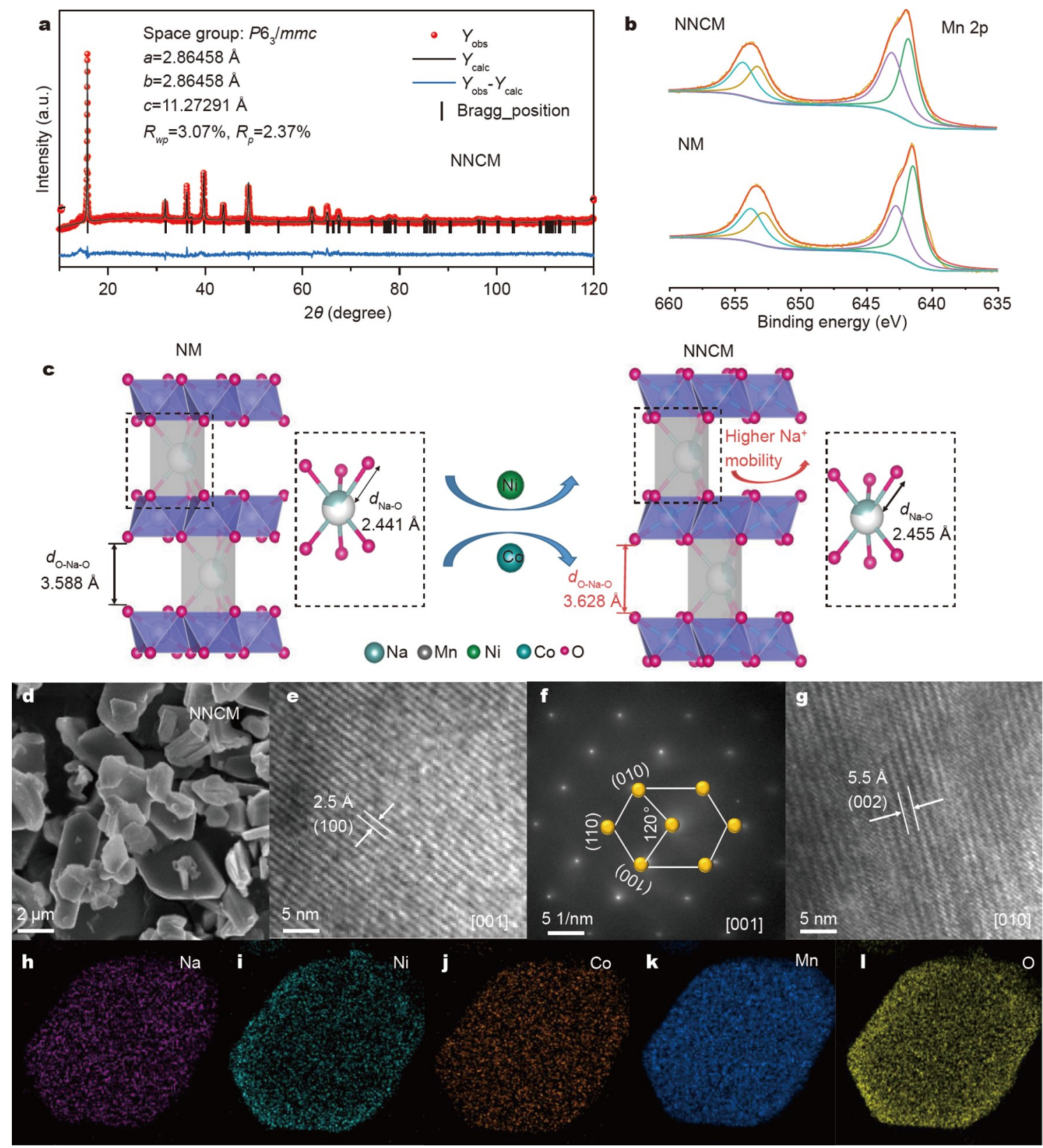

Figure 1 Structural characterisation of NM and NNCM. (a) Rietveld refinement results of the NNCM powder, (b) Mn 2p XPS fitted spectra of NM and NNCM powders, (c) schematic illustration of the effect of Ni and Co doping on the electrode structure, (d) SEM, (e and f) HRTEM image at the [001] zone axis and the corresponding SAED image, (g) HRTEM image at the [010] zone axis, and (h-l) TEM (HAADF Na, Ni, Co, Mn, and O) elemental mapping images of the NNCM powder.

shows a uniform element distribution of $\mathrm{Na}, \mathrm{Ni}, \mathrm{Co}, \mathrm{Mn}$, and $\mathrm{O}$ in the NNCM cathode material (Fig. 1h-l).

The Na-storage electrochemical properties of NNCM and NM compounds were systematically cycled as the cathode in half cells at 25 and $-20^{\circ} \mathrm{C}$. Fig. $2 \mathrm{a}$ presents the room-temperature (RT) galvanostatic charge/discharge profiles and the corresponding $\mathrm{d} Q / \mathrm{d} V$ plots upon cycling. In $1.5-4.2 \mathrm{~V}$ at $0.2 \mathrm{C}$, the NNCM samples provided a discharge-specific capacity of $181.5 \mathrm{~mA} \mathrm{~h} \mathrm{~g}^{-1}$, which is $<207.1 \mathrm{~mA} \mathrm{~h} \mathrm{~g}^{-1}$ for NM. The chargedischarge curves and the corresponding $\mathrm{d} Q / \mathrm{d} V$ plots of the NM samples exhibiting complex voltage plateaus and steps transformed into relatively highly smoother charge-discharge curves after substitution and cycling, and in particular, the clear sloping line observed over $2 \mathrm{~V}$. Similarly, the voltage plateaus of the NM samples remained complex when the ambient temperature decreased to $-20^{\circ} \mathrm{C}$ (Fig. 2b) (denoted as NM-LT and NNCMLT). The curve corresponding to NNCM-LT is a complete sloping line. Moreover, NNCM-LT exhibited an ultrahigh LTspecific capacity $\left(147.4 \mathrm{~mA} \mathrm{~h} \mathrm{~g}^{-1}\right)$, thereby outperforming NMLT electrodes $\left(108.3 \mathrm{~mA} \mathrm{~h} \mathrm{~g}^{-1}\right)$. These high performance results indicate the transformation of the electrochemical behaviour to capacitor behaviour, effective suppression of $\mathrm{Na}^{+} /$vacancy ordered rearrangement, and phase transition. The compounds with a single element (Co or $\mathrm{Ni}$ ) occupied in $\mathrm{Mn}$ sites maintained the $\mathrm{Na}^{+} /$vacancy ordered behaviour (Fig. S8). These findings again confirm that $\mathrm{TM}$ ions $\left(\mathrm{Mn}^{3+}, \mathrm{Ni}^{2+}\right.$, and $\left.\mathrm{Co}^{3+}\right)$ with 

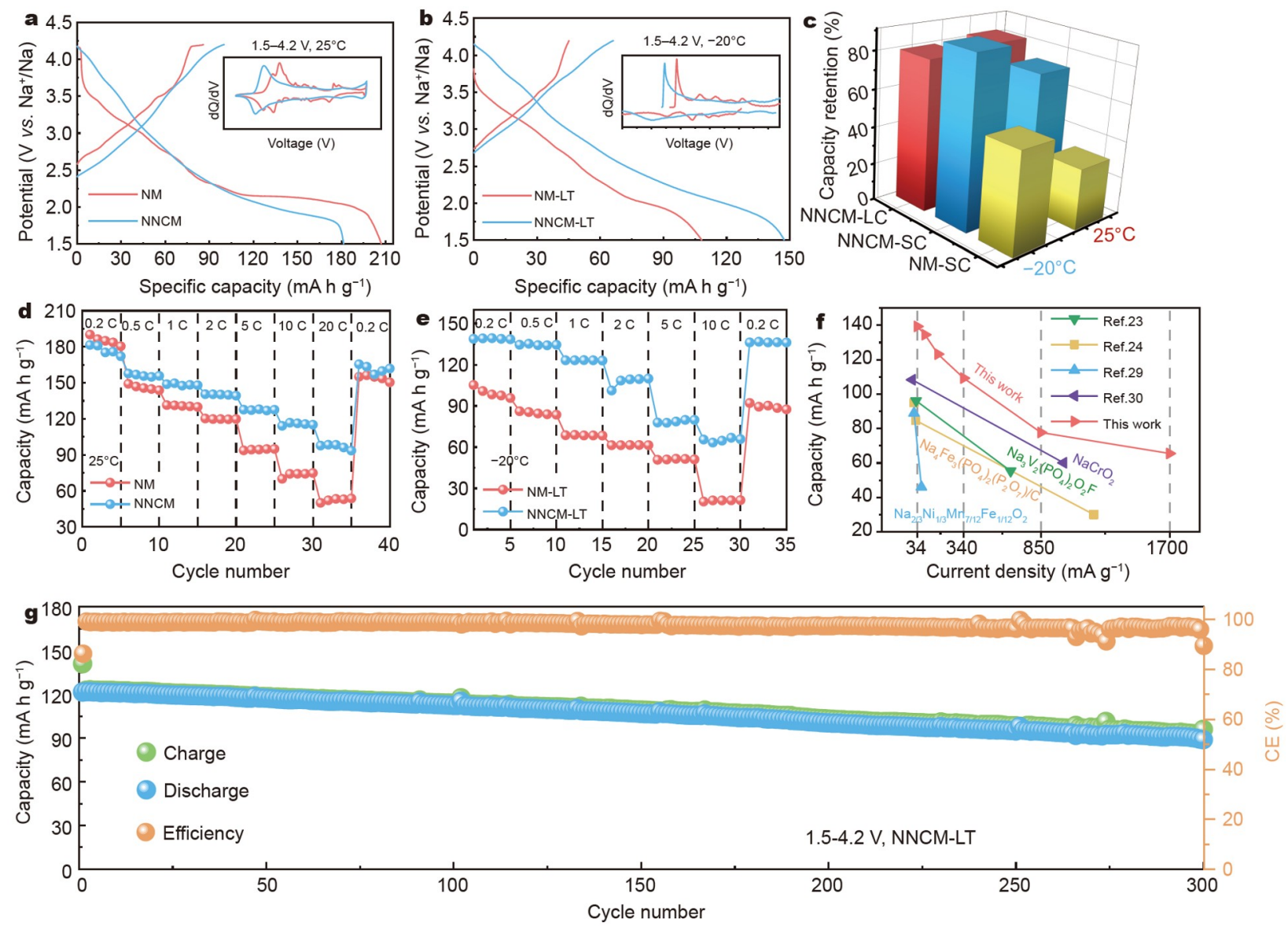

Figure 2 Electrochemical characterisations of the NM and NNCM electrodes in Na half cells at 25 and $-20^{\circ} \mathrm{C}$. (a and b) Galvanostatic charge/discharge curves and $\mathrm{d} Q / \mathrm{d} V$ profiles (inset) at $0.2 \mathrm{C}$. (c) Capacity retentions corresponding to various cycles (SC: 100 cycles; LC: 300 cycles). (d and e) Rate capabilities at different rates. (f) Rate performance compared with some advanced electrodes at LT. (g) Long-term cycle performance of NNCM-LT at 1 C.

highly similar ionic radii $\left(\mathrm{Co}^{3+}=6.1 \AA \mathrm{Ni}^{2+}=6.9 \AA\right.$, and $\mathrm{Mn}^{3+}=$ $6.5 \AA$ Å) and substantially different redox potentials $(\sim 3 \mathrm{~V}$ for $\mathrm{Co}^{3+/ 4+}, \sim 3.3 / 3.7 \mathrm{~V}$ for $\mathrm{Ni}^{2+/ 3+/ 4+}$, and $\sim 2.3 \mathrm{~V}$ for $\mathrm{Mn}^{3+/ 4+}$ ) build the P2-layered oxide-free $\mathrm{Na}^{+} /$vacancy ordering, which can extend the complete solid solution zone over a wide $\mathrm{Na}$ intercalation range, thus ensuring rapid $\mathrm{Na}^{+}$mobility $[25,27,28]$. Fig. S9 presents their corresponding CV curves. The CV of NM shows a sharp peak after $4 \mathrm{~V}$, corresponding to the unfavourable phase transition from $\mathrm{P} 2$ to $\mathrm{O} 2$ at $25^{\circ} \mathrm{C}$. Additionally, the distinct polarisation voltage $(805 \mathrm{mV})$ for NM-LT indicated an unstable structure at $-20^{\circ} \mathrm{C}$. The NNCM samples resembled capacitors and exhibited low polarisation voltage $(485 \mathrm{mV})$. After 100 cycles at $0.5 \mathrm{C}$ (Fig. S10a and S10b), NNCM exhibited excellent capacity retention (NNCM: 74\%; NNCM-LT: 91\%). By contrast, the NM samples showed the capacity retention of only $32.2 \%$ at $25^{\circ} \mathrm{C}$. Although the NM electrode performed well during 90 cycles, the LT cell broke after the 98th cycle. The charge-discharge curves showed distinct overcharge caused by the complicated LT effect (slow kinetics and solvation/desolvation processes), which led to the disruption of sodium cathode material stability (Fig. S10c). The LT effect caused a decrease in the ionic conductivity and an increase in the transfer resistance, thus leading to the difficult $\mathrm{Na}$-intercalation/extraction and irreversible gliding of oxygen layers. Then, the lattice mismatch and dislocations formed, which ultimately marred the electrochemical performance. By contrast, the NNCM-LT material, which exhibited sloping lines without discharge voltage plateaus, showed a typical solid-solution reaction, where variations in the volume and lattice parameters were negligible, and excellent kinetics after cycling (Fig. S10d). The NNCM compounds showed an outstanding capacity retention of $82.3 \%$ after 200 cycles at $2 \mathrm{C}$ and $1.5-4.2 \mathrm{~V}$ and a stable Coulombic efficiency (Fig. S11). The LT-capacity retention for NNCM reached $80 \%$ after 300 cycles at $1 \mathrm{C}$ (Fig. 2g). Fig. 2c illustrates the detailed capacity retentions at various cycles (LC: long cycle; SC: short cycle). To further investigate rate properties, the NM and NNCM electrodes were compared at various rates (Fig. 2d). NNCM provided the reversible discharge capacities of 180.9, $156.8,148.8,140.2,127.6,116.2$, and $98.4 \mathrm{~mA} \mathrm{~h} \mathrm{~g}^{-1}$ at $0.2,0.5,1$, $2,5,10$, and $20 \mathrm{C}$, respectively. By contrast, NM offered the reversible capacities of only 74.2 and $53 \mathrm{~mA} \mathrm{~h} \mathrm{~g}^{-1}$ at 10 and $20 \mathrm{C}$, respectively. NNCM-LT exhibited an excellent LT rate (Fig. 2e), with the discharge capacities of $123.2,79.8$, and $66.8 \mathrm{~mA} \mathrm{~h} \mathrm{~g}^{-1}$ at 1,5 , and $10 \mathrm{C}$, respectively, which surpassed those capacities of NM-LT and some previously reported sodium cathode materials $[23,24,29,30]$.

To further understand the reason for excellent electrochemical performance, especially for outstanding LT properties, we investigated the NNCM electrode kinetics irrespective of RT or LTs. The CV of NNCM and NNCM-LT was measured at various scan rates (Fig. 3a and d). With an increase in the scan rate, the cathodic and anodic peaks shifted to relatively low and high 

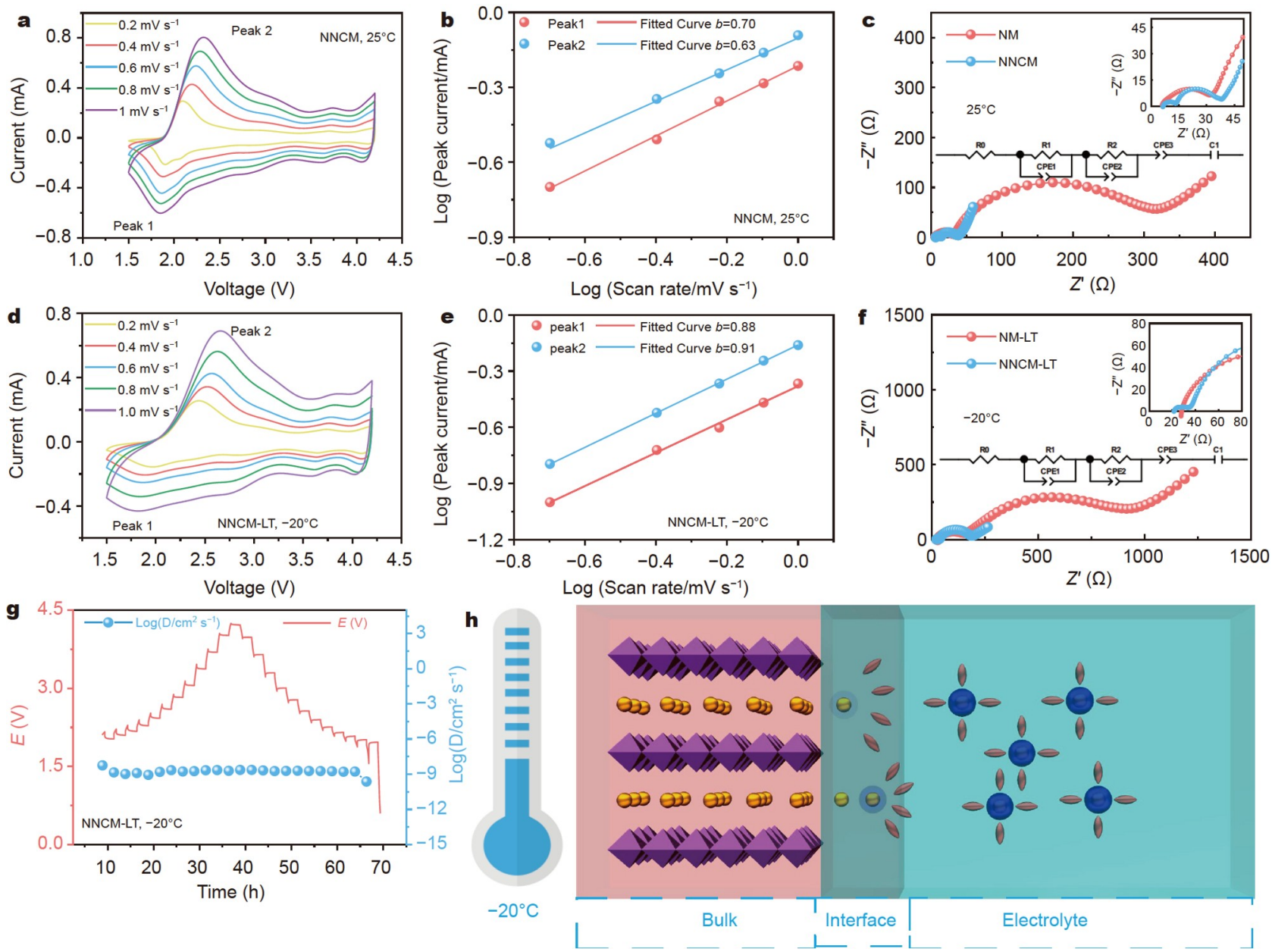

Figure 3 Kinetics analyses of sodium storage for the NNCM electrode at 25 and $-20^{\circ} \mathrm{C}$. CV of (a) NNCM and (d) NNCM-LT electrode responses with various scan rates of $0.2-1 \mathrm{mV} \mathrm{s}^{-1}$. Determination of the $b$ value for (b) NNCM and (e) NNCM-LT electrodes according to the $\log (v)-\log (i)$ relationship. EIS curves of (c) NNCM and (f) NNCM-LT electrodes. GITT curves of (g) NNCM-LT electrodes. (h) Sodiation with the synergistic effect of the surface-controlled intercalation pseudocapacitive behaviour at the interface and high diffusion coefficient in the bulk electrode.

potential ranges, respectively, indicating the presence of combined diffusion-controlled and capacitive behaviours. In theory, the scan rate $(v)$ and the measured current $(i)$ comply with Equations (3-6) proposed by Dunn's group [31,32]:

$i=a v^{b}$

$\log (i)=b \log (v)+\log (a)$,

where $a$ and $b$ are the empirical parameters, and $i$ is the peak current. The $b$ value can be determined by plotting a $\log (i)-$ $\log (v)$ graph. The $b$ value of 0.5 indicates a diffusion-controlled process, and when the $b$ value approaches 1 , the capacitive process (surface-driven behaviour) becomes dominant. We calculated the $b$ value at the oxidation peaks of 2.12 and $2.25 \mathrm{~V}$ and at the reduction peak of $1.78 \mathrm{~V}$ (Fig. $3 \mathrm{~b}$ and e). The $b$ values of both the NNCM and NNCM-LT electrodes are $>0.5$, indicating that the kinetics are primarily surface-controlled intercalation pseudocapacitive behaviour, and thus, are fast.

$i=k_{1} v^{1 / 2}+k_{2} v$,

$i / v^{1 / 2}=k_{1}+k_{2} v^{1 / 2}$,

where $k_{1}$ and $k_{2}$ are constants, $k_{2} v$ and $k_{1} v^{1 / 2}$ represent the contribution rates of capacitance and Faradaic intercalation in the electrochemical reaction, respectively. The NNCM and NNCM-LT electrodes exhibited high capacitive behaviour ratios at all the rates (Fig. S12). Such features can help overcome the problem of slow solid-diffusion in the electrolyte/electrode interface, which is often considered an impeding factor for SIB operations at LT [16]. EIS was used to evaluate the transport kinetics (Fig. $3 c$ and $\mathrm{f}$ ). According to the combined EIS and $\mathrm{Z}$ view software analyses, one branch, representing the first semicircle at mid frequencies, showed the desolvation behaviour at the interface. The second semi-circle at mid frequencies exhibited the charge transfer phenomenon occurring at the electrode. The second branch comprised a diffusion element at low frequencies [33]. Therefore, the resistive contribution described using the equivalent circuit model can be divided into three major categories: high-frequency Ohmic resistance $\left(R_{0}\right)$, solid electrolyte interphase resistance $\left(R_{1}\right)$, and charge transfer resistance $\left(R_{2}\right)$. Table S3 presents all the resistances of NNCM calculated from the EIS data. The optimised ionic and electronic pathways were obtained for the modified compounds with disordered structures (Table S3). When the cycling temperature decreased to $-20^{\circ} \mathrm{C}$, the small variation in $R_{1}$ values and low charge-transfer resistance of the NNCM electrode provided stable desolvation and relatively higher electro-activities at the 
interface, which indicated a high LT rate capacity and cycling stability [34]. To further probe the $\mathrm{Na}^{+}$diffusion coefficient $\left(D_{\mathrm{Na}}{ }^{+}\right)$of NNCM-LT and other samples, GITT was conducted (Fig. $3 \mathrm{~g}$ and Fig. S13). The $D_{\mathrm{Na}}{ }^{+}$value determined from GITT for NNCM was approximately $10^{-9}-10^{-7.5} \mathrm{~cm}^{2} \mathrm{~s}^{-1}$, which is three orders of magnitude higher than $\mathrm{D}_{\mathrm{Na}}{ }^{+}$for $\mathrm{NM}\left(10^{-12.5}\right.$ $10^{-10.5} \mathrm{~cm}^{2} \mathrm{~s}^{-1}$ ) at $25^{\circ} \mathrm{C}$. When the temperature decreased to $-20^{\circ} \mathrm{C}, D_{\mathrm{Na}}{ }^{+}$for NNCM-LT remained within $10^{-9}-10^{-7.5} \mathrm{~cm}^{2} \mathrm{~s}^{-1}$, and that for NM-LT $\left(10^{-13.5}-10^{-11} \mathrm{~cm}^{2} \mathrm{~s}^{-1}\right)$ decreased to an order of magnitude lower than that for NM. Moreover, no jumps were observed in $\mathrm{Na}$ diffusion coefficient values for NNCM-LT, which can be attributed to Na-vacancy disorder in the bulk and is consistent with the sloping characteristic of electrochemical curves. Fig. 3h illustrates the sodiation of the NNCM electrode. $\mathrm{Na}$-vacancy disorder led to the solid solution reaction in the bulk electrode, and the pseudocapacitive feature promoted $\mathrm{Na}^{+}$desolvation at the electrolyte/electrode interface, thus achieving high electrochemical performance at LT.

To further obtain insights into the structural evolution of the NNCM samples during desodiation/sodiation, in situ XRD was employed at $0.2 \mathrm{C}$ and $1.5-4.2 \mathrm{~V}$ during the initial cycle (Fig. 4a). Fig. $4 \mathrm{~b}$ illustrates the corresponding lattice constants ( $a$ and $c$ ). When sodium ions were extracted, no new peaks appeared, but the (002) and (004) peaks of NNCM consecutively shifted towards a relatively low angle. By contrast, the (100) and (102) diffraction lines shifted towards a relatively high angle. During discharge, the shifted diffraction peaks regained their original position, which confirmed the structural robustness of NNCM after cycling. The (004) diffraction lines did not appear in any peak split or shape change, which indicated the absolute solidsolution behaviour of NNCM [27]. The volume change of unit cells obtained before and after $\mathrm{Na}^{+}$extraction was only $1.4 \%$, which accounted for the durable electrochemical performance
[35]. Therefore, double atoms (Co and $\mathrm{Ni}$ ) diminished phase transformation after cycling. Such a solid-solution behaviour provides excellent kinetic transportation.

From DFT, we calculated the projected density of states (pDOS) for $3 \mathrm{~d}$ orbitals of TMs and $2 \mathrm{p}$ orbitals of oxygen. In theory, TM and $\mathrm{O}$ atoms have octahedral coordination $\left(\mathrm{TMO}_{6}\right.$ octahedral structure) in layered TM oxides, and the energy levels of $3 \mathrm{~d}$ orbitals of the central TM ions split into two orbitals, a high-energy $e_{g}$ orbital and low-energy $t_{2 g}$ orbital [36]. Mn ions show distinct energy levels for different samples (Fig. 5a). In NNCM, Mn ions exhibit a high oxidation state $\left(\mathrm{Mn}^{4+}: \mathrm{t}_{2 \mathrm{~g}}{ }^{3} \mathrm{e}_{\mathrm{g}}{ }^{0}\right)$, and in the $\mathrm{NM}$, they show $\mathrm{Mn}^{3+}: \mathrm{t}_{2 \mathrm{~g}}{ }^{3} \mathrm{e}_{\mathrm{g}}{ }^{1} \cdot \mathrm{Mn}^{3+}$ with unpaired electrons exhibits a strong Jahn-Teller activity, which leads to orbital, spin, and charge ordering, thereby restricting desodiation/sodiation [37]. Furthermore, the calculated total DFT energy shows that $\mathrm{Ni} / \mathrm{Co} / \mathrm{Mn}$ mixing results in a considerable decrease in the site energy difference from $\mathrm{Na}_{\mathrm{e}}$ to $\mathrm{Na}_{\mathrm{f}}$, and thus, promotes the occurrence of $\mathrm{Na}^{+} /$vacancy order-disorder [25] (Fig. $5 b$ and c).

Finally, to investigate its application in LT full cells, the NNCM cathode was coupled with a hard carbon (HC) anode (the mass ratio of 1.2:1) (Fig. 6a). Before assembling the full battery, the solid-electrolyte formation must be facilitated through presodiation for the HC anode. The full battery at RT exhibits a high reversible specific capacity of $178.5 \mathrm{~mA} \mathrm{~h} \mathrm{~g}^{-1}$ with a specific energy of $449 \mathrm{~W} \mathrm{~h} \mathrm{~kg}^{-1}$ at $0.2 \mathrm{C}$ in $1.4-4.1 \mathrm{~V}$ based on the cathode mass (Fig. 6b). The full battery shows a reversible specific capacity of $142.4 \mathrm{~mA} \mathrm{~h} \mathrm{~g}^{-1}$ at $-20^{\circ} \mathrm{C}$, corresponding to an energy density of $358.3 \mathrm{Wh} \mathrm{kg}^{-1}$, which is $79.8 \%$ of its RT capacity. Fig. $6 \mathrm{c}$ and d illustrate the rate properties. At $0.2,0.5,1$, 2,5 , and $10 \mathrm{C}$, the RT full cell can offer the reversible capacities of $178.5,158.7,148.4,134.9,114.9$, and $92 \mathrm{~mA} \mathrm{~h} \mathrm{~g}^{-1}$, respectively, and its LT rate capacities are $79.8 \%, 77 \%, 67 \%, 53.7 \%, 61.9 \%$,
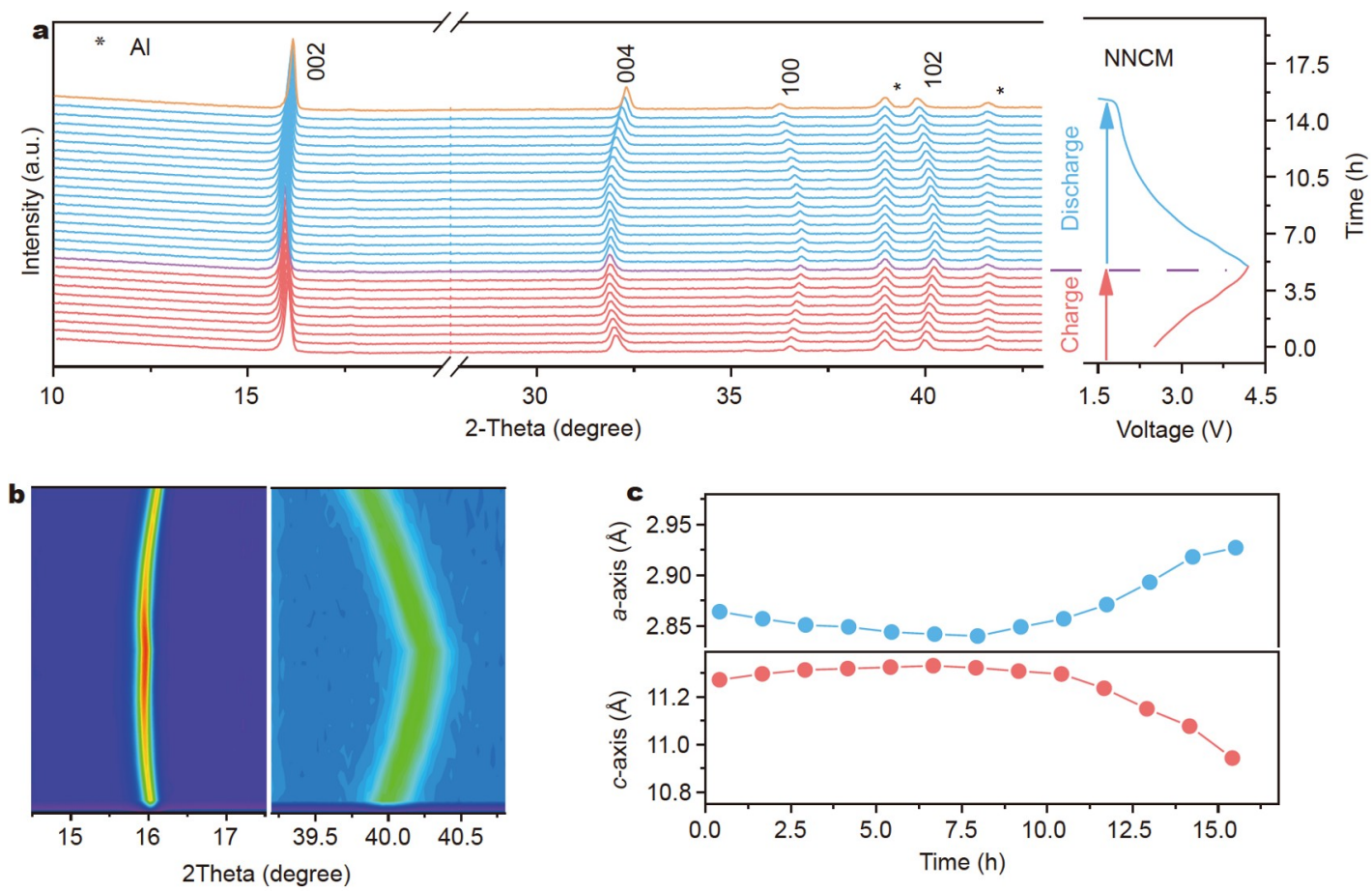

Figure 4 Crystal structural evolution of NNCM after $\mathrm{Na}^{+}$extraction/insertion. (a) In situ XRD patterns collected during the first charge/discharge cycle of the NNCM electrode at $0.2 \mathrm{C}$ and $1.5-4.2 \mathrm{~V}$. (b) The corresponding contour map for the evolution of the main characteristic diffraction peaks. (c) Variation in the lattice constant along with $\mathrm{Na}^{+}$extraction and insertion for NNCM. 

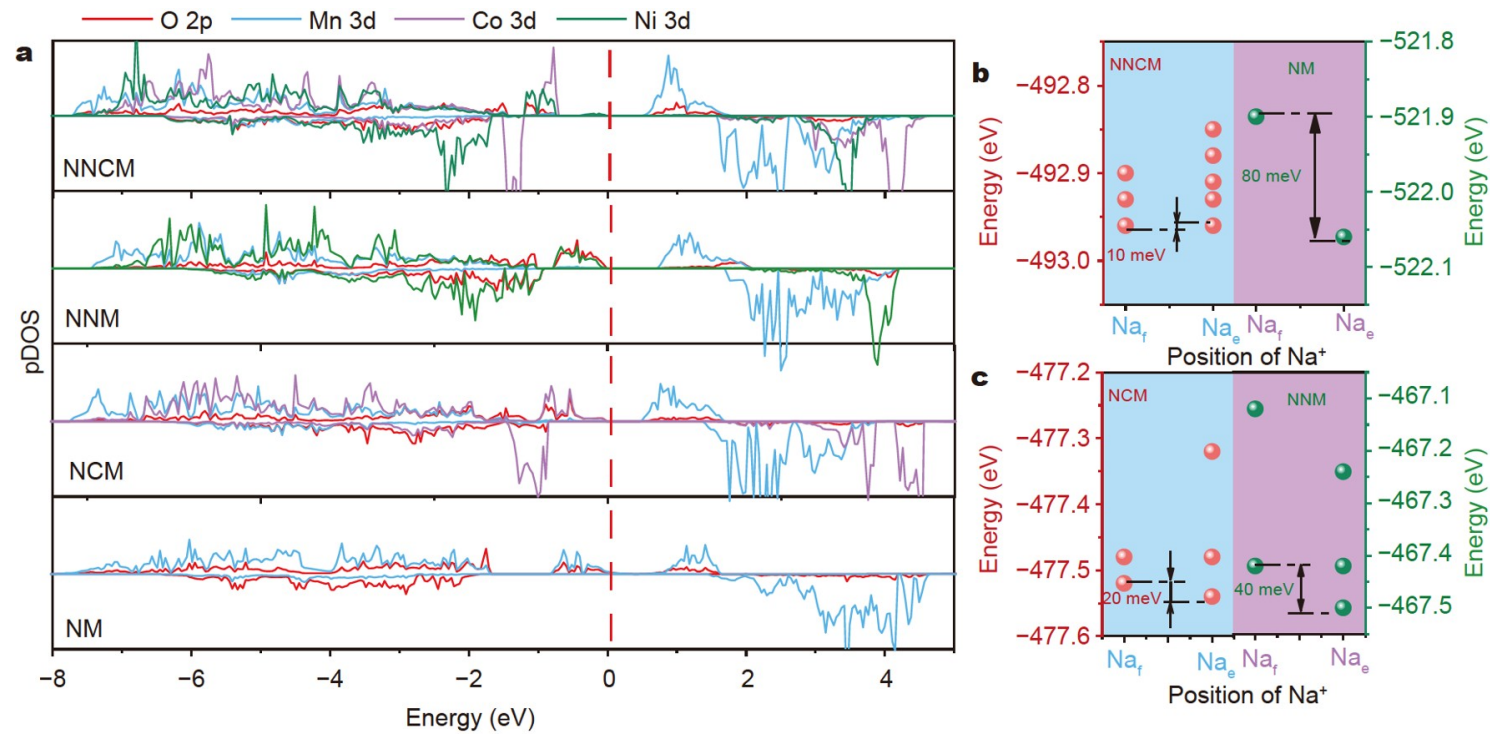

Figure 5 (a) Projected density of states of NM, NCM, NNM and NNCM. (b and c) Calculated energy difference between $\mathrm{Na}_{\mathrm{e}}$ and $\mathrm{Na}_{\mathrm{f}}$ sites for NM, NCM, NNM, and NNCM.

a
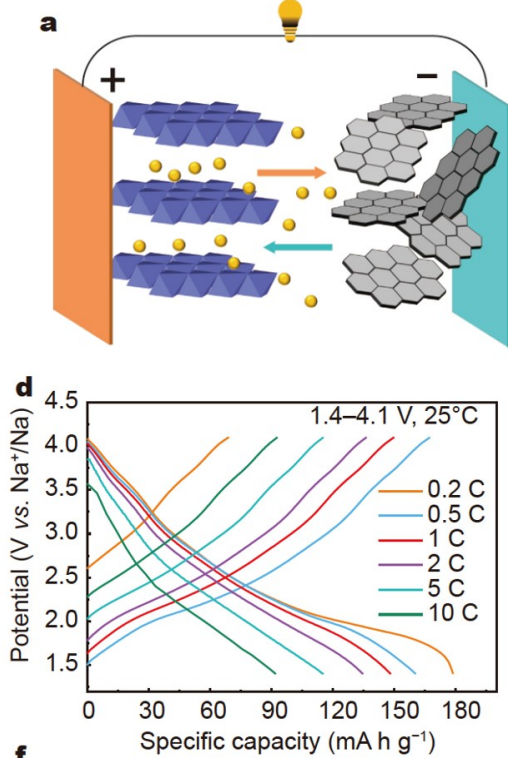

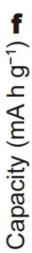

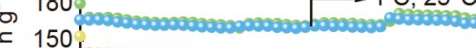

120

90
60
30

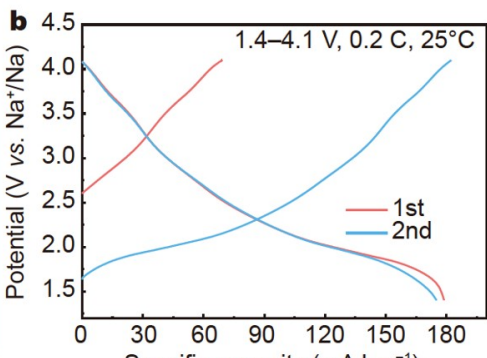

Specific capacity $\left(\mathrm{mA} \mathrm{h} \mathrm{g}^{-1}\right)$
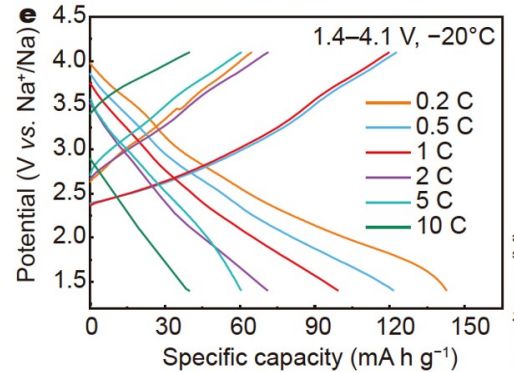

$1.4-4.1 \mathrm{~V}$

$1.4-4.1 \mathrm{~V}$
$0.5 \mathrm{C},-20^{\circ} \mathrm{C} \longleftarrow$

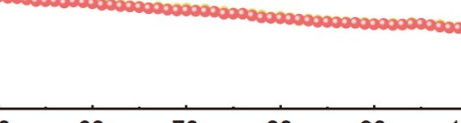

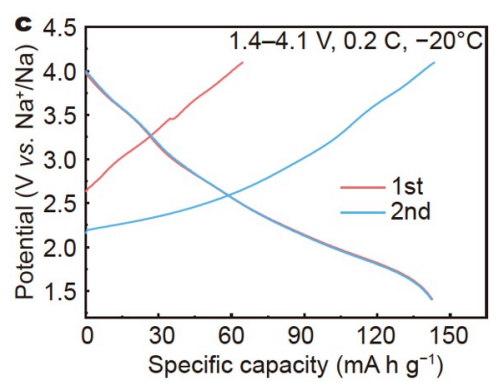

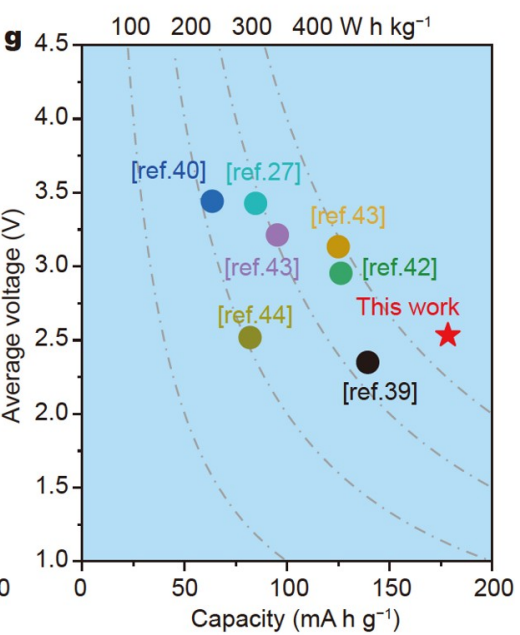

Figure 6 Full cell performance of the NNCM electrode at 25 and $-20^{\circ} \mathrm{C}$. (a) Na-ion full cell coupled with NNCM as the cathode and HC as the anode. (b and c) Charge/discharge curves of the full cell in 1.4-4.1 V at 0.2 C. ( $\mathrm{d}$ and e) Various rate curves of NNCM//HC. (f) Cycle performance of the full cell at 0.5 and $1 \mathrm{C}$ during 100 cycles. (g) Full cell performance of NNCM and other available Na-ion battery systems based on the cathode mass. All the reported data are converted into the capacity by using the same method.

and $43.5 \%$ of its RT capacities, respectively, which further confirms its superior rate capacity. Our NNCM electrode with enhanced $\mathrm{Na}^{+}$diffusivity exhibits an excellent long-term cycle, and its capacity retention is $93 \%$ at $1 \mathrm{C}$ and $25^{\circ} \mathrm{C}$ and $68.2 \%$ at $0.5 \mathrm{C}$ and $-20^{\circ} \mathrm{C}$ (Fig. 6f). Our NNCM//HC full cell is outstanding and comparable to most previously reported full cells
(Fig. 6g) [38-44]. These results indicate that the NNCM electrode is feasible and prospective for high-energy-storage systems.

\section{CONCLUSIONS}

We studied the LT electrochemical properties and storage 
mechanism of P2-type Mn-based layered cathode oxides through various cycling measurements and kinetic analyses. In the crystal framework, LT electrochemical performance was highly hindered due to $\mathrm{Na}^{+} /$vacancy order, which induced slow LT $\mathrm{Na}^{+}$mobility and solvation/desolvation, leading to high transfer resistances, difficult $\mathrm{Na}$-intercalation/extraction, and irreversible gliding of oxygen layers. Eventually, lattice mismatch and dislocations occurred. Therefore, we designed the LT P2type layered cathode material through optimal structure modulation with the partial element substitution of $\mathrm{Ni}$ and $\mathrm{Co}$ into Mn sites. DFT calculations demonstrated that the double atoms (Co and Ni) highly inhibited the Jahn-Teller activity of Mn ions, minimised the site energy difference between $\mathrm{Na}_{e}$ and $\mathrm{Na}$, and increased the difference in Fermi levels between TMs, thereby increasing the degree of $\mathrm{Na}$-vacancy disorders and enlarging interstitial spaces. With its open ionic channels and enlarged $\mathrm{Na}$ interlayers, NNCM exhibits high $\mathrm{Na}^{+}$diffusion coefficients (approximately $10^{-8} \mathrm{~cm}^{2} \mathrm{~s}^{-1}$ at $25^{\circ} \mathrm{C}$ and $10^{-9} \mathrm{~cm}^{2} \mathrm{~s}^{-1}$ at $-20^{\circ} \mathrm{C}$ ) and intercalation pseudocapacitive behaviour, which provides excellent LT electrochemical properties for SIBs. Consequently, unique electrodes offer brilliant LT electrochemical properties. Our findings shed light on the applications of energy-storage systems and make progress towards SIB commercialisation.

\section{Received 21 April 2021; accepted 17 June 2021; published online 4 August 2021}

1 Hwang JY, Myung ST, Sun YK. Sodium-ion batteries: present and future. Chem Soc Rev, 2017, 46: 3529-3614

2 Wang X, Roy S, Shi Q, et al. Progress in and application prospects of advanced and cost-effective iron $(\mathrm{Fe})$-based cathode materials for sodium-ion batteries. J Mater Chem A, 2021, 9: 1938-1969

3 Wang $\mathrm{C}$, Du D, Song $\mathrm{M}$, et al. A high-power $\mathrm{Na}_{3} \mathrm{~V}_{2}\left(\mathrm{PO}_{4}\right)_{3}$-Bi sodiumion full battery in a wide temperature range. Adv Energy Mater, 2019, 9: 1900022

4 Wang YY, Hou BH, Guo JZ, et al. An ultralong lifespan and lowtemperature workable sodium-ion full battery for stationary energy storage. Adv Energy Mater, 2018, 8: 1703252

5 Hou BH, Wang YY, Liu DS, et al. N-doped carbon-coated $\mathrm{Ni}_{1.8} \mathrm{Co}_{1.2} \mathrm{Se}_{4}$ nanoaggregates encapsulated in $\mathrm{N}$-doped carbon nanoboxes as advanced anode with outstanding high-rate and low-temperature performance for sodium-ion half/full batteries. Adv Funct Mater, 2018, 28: 1805444

6 Zhao N, Zhang F, Zhan $\mathrm{F}$, et al. $\mathrm{Fe}^{3+}$-stabilized $\mathrm{Ti}_{3} \mathrm{C}_{2} \mathrm{~T}$ MXene enables ultrastable Li-ion storage at low temperature. J Mater Sci Tech, 2021, 67: $156-164$

7 Hou J, Yang M, Wang D, et al. Fundamentals and challenges of lithium ion batteries at temperatures between -40 and $60{ }^{\circ} \mathrm{C}$. Adv Energy Mater, 2020, 10: 1904152

8 Gupta A, Manthiram A. Designing advanced lithium-based batteries for low-temperature conditions. Adv Energy Mater, 2020, 10: 2001972

9 Nian Q, Wang J, Liu S, et al. Aqueous batteries operated at $-50^{\circ} \mathrm{C}$. Angew Chem Int Ed, 2019, 58: 16994-16999

10 Hwang JY, Oh SM, Myung ST, et al. Radially aligned hierarchical columnar structure as a cathode material for high energy density sodiumion batteries. Nat Commun, 2015, 6: 6865

11 Li Y, Shi Q, Yin X, et al. Construction nasicon-type $\mathrm{NaTi}_{2}\left(\mathrm{PO}_{4}\right)_{3}$ nanoshell on the surface of P2-type $\mathrm{Na}_{0.67} \mathrm{Co}_{0.2} \mathrm{Mn}_{0.8} \mathrm{O}_{2}$ cathode for superior room/low-temperature sodium storage. Chem Eng J, 2020, 402: 126181

12 Yin X, Sarkar S, Shi S, et al. Recent progress in advanced organic electrode materials for sodium-ion batteries: Synthesis, mechanisms, challenges and perspectives. Adv Funct Mater, 2020, 30: 1908445

13 Shen L, Li Y, Roy S, et al. A robust carbon coating of $\mathrm{Na}_{3} \mathrm{~V}_{2}\left(\mathrm{PO}_{4}\right)_{3}$ cathode material for high performance sodium-ion batteries. Chin
Chem Lett, 2021, doi: 10.1016/j.cclet.2021.03.005

14 Dong $\mathrm{X}$, Lin $\mathrm{Y}$, Li $\mathrm{P}$, et al. High-energy rechargeable metallic lithium battery at $-70{ }^{\circ} \mathrm{C}$ enabled by a cosolvent electrolyte. Angew Chem Int Ed, 2019, 58: 5623-5627

15 Shen L, Shi S, Roy S, et al. Recent advances and optimization strategies on the electrolytes for hard carbon and P-based sodium-ion batteries. Adv Funct Mater, 2020, 31: 2006066

16 Jin $\mathrm{Y}, \mathrm{Xu} \mathrm{Y}$, Le PML, et al. Highly reversible sodium ion batteries enabled by stable electrolyte-electrode interphases. ACS Energy Lett, 2020, 5: 3212-3220

17 Yue R, Xia F, Qi R, et al. Trace Nb-doped $\mathrm{Na}_{0.7} \mathrm{Ni}_{0.3} \mathrm{Co}_{0.1} \mathrm{Mn}_{0.6} \mathrm{O}_{2}$ with suppressed voltage decay and enhanced low temperature performance. Chin Chem Lett, 2021, 32: 849-853

18 Tie D, Gao G, Xia F, et al. Modulating the interlayer spacing and $\mathrm{Na}^{+} /$ vacancy disordering of $\mathrm{P} 2-\mathrm{Na}_{0.67} \mathrm{MnO}_{2}$ for fast diffusion and high-rate sodium storage. ACS Appl Mater Interfaces, 2019, 11: 6978-6985

19 Dong X, Yang Y, Wang B, et al. Low-temperature charge/discharge of rechargeable battery realized by intercalation pseudocapacitive behavior. Adv Sci, 2020, 7: 2000196

20 Gao G, Tie $\mathrm{D}, \mathrm{Ma} \mathrm{H}$, et al. Interface-rich mixed $\mathrm{P} 2+\mathrm{T}$ phase $\mathrm{Na}_{x} \mathrm{Co}_{0.1} \mathrm{Mn}_{0.9} \mathrm{O}_{2}(0.44 \leq x \leq 0.7)$ toward fast and high capacity sodium storage. J Mater Chem A, 2018, 6: 6675-6684

21 You Y, Yao HR, Xin S, et al. Subzero-temperature cathode for a sodium-ion battery. Adv Mater, 2016, 28: 7243-7248

22 Rui X, Zhang X, Xu S, et al. A low-temperature sodium-ion full battery: Superb kinetics and cycling stability. Adv Funct Mater, 2020, 31: 2009458

23 Guo JZ, Wang PF, Wu XL, et al. High-energy/power and low-temperature cathode for sodium-ion batteries: In situ XRD study and superior full-cell performance. Adv Mater, 2017, 29: 1701968

24 Chen M, Hua W, Xiao J, et al. NASICON-type air-stable and all-climate cathode for sodium-ion batteries with low cost and high-power density. Nat Commun, 2019, 10: 1480

25 Wang PF, Yao HR, Liu XY, et al. $\mathrm{Na}^{+} /$vacancy disordering promises high-rate Na-ion batteries. Sci Adv, 2018, 4: eaar6018

26 Hwang J, Kim J, Yu T, et al. A new P2-type layered oxide cathode with extremely high energy density for sodium-ion batteries. Adv Energy Mater, 2019, 9: 1803346

27 Xiao Y, Zhu Y, Yao H, et al. A stable layered oxide cathode material for high-performance sodium-ion battery. Adv Energy Mater, 2019, 9: 1803978

28 Wang Y, Xiao R, Hu YS, et al. $\mathrm{P} 2-\mathrm{Na}_{0.6}\left[\mathrm{Cr}_{0.6} \mathrm{Ti}_{0.4}\right] \mathrm{O}_{2}$ cation-disordered electrode for high-rate symmetric rechargeable sodium-ion batteries. Nat Commun, 2015, 6: 6954

29 Yang Q, Wang PF, Guo JZ, et al. Advanced P2- $\mathrm{Na}_{2 / 3} \mathrm{Ni}_{1 / 3} \mathrm{Mn}_{7 / 12} \mathrm{Fe}_{1 / 12} \mathrm{O}_{2}$ cathode material with suppressed $\mathrm{P} 2-\mathrm{O}_{2}$ phase transition toward highperformance sodium-ion battery. ACS Appl Mater Interfaces, 2018, 10: $34272-34282$

30 Liang L, Sun X, Denis DK, et al. Ultralong layered $\mathrm{NaCrO}_{2}$ nanowires: A competitive wide-temperature-operating cathode for extraordinary high-rate sodium-ion batteries. ACS Appl Mater Interfaces, 2019, 11: 4037-4046

31 Augustyn V, Come J, Lowe MA, et al. High-rate electrochemical energy storage through $\mathrm{Li}^{+}$intercalation pseudocapacitance. Nat Mater, 2013, 12: $518-522$

32 Choi C, Ashby DS, Butts DM, et al. Achieving high energy density and high power density with pseudocapacitive materials. Nat Rev Mater, 2019, 5: 5-19

33 Laforgue A, Yuan XZ, Platt A, et al. Effects of fast charging at low temperature on a high energy Li-ion battery. J Electrochem Soc, 2020, 167: 140521

34 Liao B, Li H, Xu M, et al. Designing low impedance interface films simultaneously on anode and cathode for high energy batteries. Adv Energy Mater, 2018, 8: 1800802

35 Jin T, Wang PF, Wang QC, et al. Realizing complete solid-solution reaction in high sodium content P2-type cathode for high-performance sodium-ion batteries. Angew Chem Int Ed, 2020, 59: 14511-14516

36 Sun G, Yu FD, Que LF, et al. Local electronic structure modulation 
enhances operating voltage in Li-rich cathodes. Nano Energy, 2019, 66: 104102

37 Radin MD, Van der Ven A. Simulating charge, spin, and orbital ordering: Application to Jahn-Teller distortions in layered transitionmetal oxides. Chem Mater, 2018, 30: 607-618

38 Li X, Ma X, Su D, et al. Direct visualization of the Jahn-Teller effect coupled to $\mathrm{Na}$ ordering in $\mathrm{Na}_{5 / 8} \mathrm{MnO}_{2}$. Nat Mater, 2014, 13: 586-592

39 Zhu YF, Xiao Y, Hua WB, et al. Manipulating layered P2@P3 integrated spinel structure evolution for high-performance sodium-ion batteries. Angew Chem Int Ed, 2020, 59: 9299-9304

40 Wang QC, Meng JK, Yue XY, et al. Tuning P2-structured cathode material by $\mathrm{Na}$-site $\mathrm{Mg}$ substitution for Na-ion batteries. J Am Chem Soc, 2019, 141: 840-848

41 Xiao Y, Wang PF, Yin YX, et al. Exposing $\{010\}$ active facets by multiple-layer oriented stacking nanosheets for high-performance capacitive sodium-ion oxide cathode. Adv Mater, 2018, 30: 1803765

42 Ye H, Wang CY, Zuo TT, et al. Realizing a highly stable sodium battery with dendrite-free sodium metal composite anodes and O3-type cathodes. Nano Energy, 2018, 48: 369-376

43 Zhou K, Xie Q, Li B, et al. An in-depth understanding of the effect of aluminum doping in high-nickel cathodes for lithium-ion batteries. Energy Storage Mater, 2021, 34: 229-240

$44 \mathrm{Mu} \mathrm{L}, \mathrm{Xu} \mathrm{S}$, Li Y, et al. Prototype sodium-ion batteries using an airstable and $\mathrm{Co} / \mathrm{Ni}$-free O3-layered metal oxide cathode. Adv Mater, 2015, 27: 6928-6933

Acknowledgements We thank the financial support from the National Natural Science Foundation of China (51774251), Shanghai Science and Technology Commission's “2020 Science and Technology Innovation Action Plan" (20511104003), the Natural Science Foundation of Shanghai (21ZR1424200), Hebei Natural Science Foundation for Distinguished Young Scholars (B2017203313), and Talent Engineering Training Funds of Hebei Province (A201802001).

Author contributions Zhao Y, Wang J, Hou Y and Zhang J designed and guided the work. Li Y performed the experiments. Feng X and Wang J performed the first-principles calculations. Li Y wrote the paper with support from Wang $\mathrm{X}$ and Shi Q. All authors contributed to the general discussion.

Conflict of interest The authors declare no conflict of interest.

Supplementary information Supporting data are available in the online version of the paper.

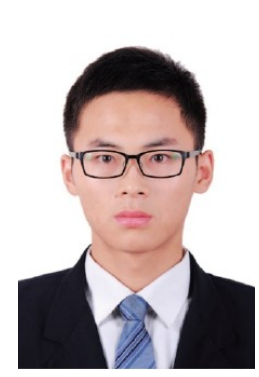

Yong Li is a PhD student of Xi'an University of Architecture and Technology under the supervision of Prof. Juan Wang. Currently, he is studying at Shanghai University as an exchange student in Prof. Yufeng Zhao's group. His research is mainly focused on the low-temperature sodium ion batteries.

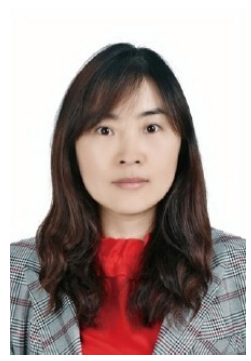

Yufeng Zhao is currently working as a professor at Shanghai University. She obtained her $\mathrm{PhD}$ from Nanyang Technological University, Singapore in 2006. Afterward, she worked at Deakin University, Australia (2006-2008) and Phillips University Marburg, Germany (2008-2009) as a research scientist. She was also a visiting professor at the Northwestern University (2014-2015). Her research mainly focuses on energy-storage materials and devices, such as nanocarbon materials, supercapacitors, and electrocatalysts.

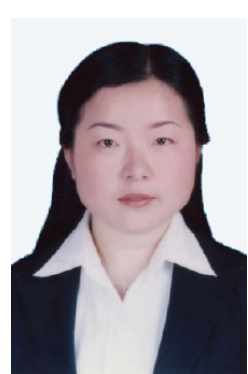

Juan Wang is currently working as a professor at Xi'an University of Architecture and Technology. She obtained her $\mathrm{PhD}$ from Xi'an University of Architecture and Technology in 2009. Afterward, she worked as a visiting research fellow at Georgia Institute of Technology (2013-2014). Her research interests focus on energy storage materials for power sources, including $\mathrm{Li}-\mathrm{S}$ battery and $\mathrm{Li} / \mathrm{Na}$-ion battery.

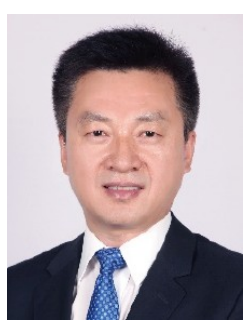

Yanglong Hou earned his $\mathrm{PhD}$ in materials science from Harbin Institute of Technology in 2000. After a short postdoctoral training at Peking University, he worked at the University of Tokyo (2002-2005) as a JSPS foreign special researcher and also at Brown University (2005-2007) as a postdoctoral researcher. He joined Peking University in 2007. His research interests include the design and chemical synthesis of functional nanoparticles, and their biomedical and energy-related applications.

\section{耐久的P2型层状氧化物正极材料的低温储钠性能研究}

李勇 ${ }^{1,2}$, 赵玉峰 $1,2^{*}$, 冯晓晨 2,3 , 王轩 ${ }^{2}$, 石钦昊 ${ }^{2}$, 王静 ${ }^{3}$, 王娟 $1^{*}$, 张久俊 ${ }^{2}$, 侯仰龙 ${ }^{*^{*}}$

摘要 为实现大规模储能, 钠离子电池不仅需要高的能量密度, 而且需 要在低温环境下依旧发挥出良好的性能. 拥有高比容量的P 2 锰基氧化 物被认为是钠离子电池中理想的候选正极材料, 但是其低温应用却很 少被探索. 本文通过合理的结构调整, 制备了具有优异低温性能的P2型 $\mathrm{Na}_{0.67} \mathrm{Ni}_{0.1} \mathrm{Co}_{0.1} \mathrm{Mn}_{0.8} \mathrm{O}_{2}$ 正极材料. 该材料表现出了优异的钠离子扩散系 数 $\left(\sim 10^{-9}-10^{-7.5} \mathrm{~cm}^{2} \mathrm{~s}^{-1},-20^{\circ} \mathrm{C}\right)$. 在半电池体系中, 该材料拥有 $147.4 \mathrm{~mA} \mathrm{~h} \mathrm{~g}^{-1}$ 的低温放电容量. 同样在 $-20^{\circ} \mathrm{C}$ 条件下, 该电极材料也展 现出能量密度为 $358.3 \mathrm{~W} \mathrm{~h} \mathrm{~kg}{ }^{-1}$ 的出色的全电池性能. 各种表征和密度 泛函理论计算表明固溶反应和㕍电容特征促进了钠离子从电极体相到 界面的扩散和脱溶剂化过程, 最终在低温条件下能够获得优异的电化 学性能. 